\title{
Non-obese-diabetic mice: immune mechanisms of pancreatic $\beta$-cell destruction
}

\author{
Y. Kanazawa ${ }^{1}$, K. Komeda ${ }^{3}$, S. Sato ${ }^{2}$, S. Mori ${ }^{2}$, K. Akanuma ${ }^{1}$ and F. Takaku ${ }^{1}$ \\ 'Third Department of Internal Medicine, Faculty of Medicine, ${ }^{2}$ Department of Pathology, Institute of Medical Sciences, University of Tokyo and \\ ${ }^{3}$ Experimental Animal Centre, Tokyo Medical College, Tokyo, Japan
}

Summary. The sequence of events shortly before the initiation of diabetes in female non-obese diabetic mice was studied. Immunologically, anti-lymphocyte antibodies appeared most frequently at 3 weeks of age and decreased thereafter. Insulin concentrations dropped after the initiation of mononuclear cell infiltration into the islets. The majority of female mice lost approximately $85 \%$ of their insulin at aged 22 weeks. Islet cell surface antibodies appeared most frequently during this period (12-18 weeks). Morphological examination revealed that mononuclear cells start to infiltrate islets at 6 weeks of age and involve major areas of the islets in females aged 22 weeks. Among these mononuclear cells, IgM-positive cells were found to be a major constituent, forming follicular (nodular) cell aggregates. T-helper and/or T-cytotoxic cells (Lyt-1-, and/or Lyt-2-positive cells) were fewer and located mainly around the follicular structures. Asialo GM1-positive lymphocytes (natural killer cells), though present, were far fewer. The process of destruction of pancreatic islets in non-obese diabetic mice is discussed with emphasis on the characteristic local immune response in the pancreas.

Key words: Non-obese diabetic mice, autoimmunity, B-lymphocyte, islet cell surface antibody, anti-lymphocyte antibodies.
Non-obese diabetic (NOD) mice were selectively bred by brother-sister mating from the ICR strain with diabetic symptoms [1]. Elevated levels of urinary glucose were observed in some of the female NOD mice at 12 weeks of age. The cumulative incidence of diabetes in females reached $80 \%$ by 30 weeks. Most of the animals that developed diabetes became ketotic within 4 weeks after diagnosis and died within 6 weeks. Only $10 \%$ of males exhibited diabetes by 30 weeks of age; ketosis and subsequent death from diabetes was rare. Although there were striking differences in the prevalence of diabetes, ketosis and mortality between males and females, mononuclear cell infiltration into the islets of Langerhans was observed equally in both sexes after 6 weeks of age. Castration of male NOD mice at age 5 weeks has been reported to increase the incidence of diabetes to the same level observed in females [2].

Previous studies have demonstrated that these animals have abnormalities which are characteristic of autoimmune diseases, such as fewer T-lymphocytes and normal numbers of B-lymphocytes in the circulation and in the spleen, and exaggerated antibody production against exogenous stimuli [3]. Morphological evidence of cellular cytotoxicity by infiltrated cells has been shown [4]. Thus the sequence of events occurring in the islets has to be analysed to clarify mechanisms of the destruction of $\beta$ cells and the pathogenesis of diabetes in female NOD mice.

\section{Materials and methods}

\begin{abstract}
Animals
NOD mice, originally obtained from the Aburabi Laboratory, Shionogi Research Institute, were bred at the Experimental Animal Centre, Tokyo Medical College in a specific pathogen-free state. Blood samples were obtained from orbital venous plexi and were placed into heparinized capillary tubes. Plasma was separated immediately. The pancreas of each animal was excised and divided into two parts, one for morphological examination and the other for extraction of insulin. These samplings were carried out at 3,6,12, 18 and 22 weeks of age from a total of 60 animals.
\end{abstract}

\section{Pancreatic insulin concentrations}

A portion of each pancreas was extracted by acid ethanol (water : ethanol : $\mathrm{HCl}-75: 23.5: 1.5$ ) and immunoreactive insulin was measured [5] after dilution of the extract against rat insulin standard and expressed as $\mathrm{ng} / \mathrm{mg}$ wet weight.

\section{Anti-lymphocyte antibodies}

Plasma anti-lymphocyte antibodies were examined by a double-antibody system using mouse lymphocytes as antigen and anti-mouse IgG (FITC) as second antibody [6]. The results were considered to be positive when more than $80 \%$ of the antigen cells were stained by FITC.

\section{Islet cell surface antibodies (ICSA)}

These antibodies were measured by the method described by Lernmark et al. [7] using RINr cells (donated by Dr. W. L. Chick, Worces- 
Table 1. Results of immunological and biochemical studies in NOD mice

\begin{tabular}{|c|c|c|c|c|c|}
\hline & \multicolumn{5}{|l|}{ Age (weeks) } \\
\hline & 3 & 6 & 12 & 18 & 22 \\
\hline Anti-lymphocytes antibodies & $5 / 9$ & $3 / 7$ & $1 / 8$ & - & - \\
\hline \multicolumn{6}{|c|}{ Pancreatic insulin concentrations (ng/mg wet weight) } \\
\hline Males & $184 \pm 16$ & $184 \pm 30(8)$ & $108 \pm 31$ & - & $97 \pm 54(3)$ \\
\hline Females & $155 \pm 16(10)$ & $208 \pm 52(6)$ & $157 \pm 56(10)$ & $52 \pm 25(6)$ & $46 \pm 51(4)$ \\
\hline
\end{tabular}

The number of antibody positive tests out of the total number of mice tested at each age is shown.

Insulin concentrations are expressed as mean \pm SD with number of mice studied in parentheses
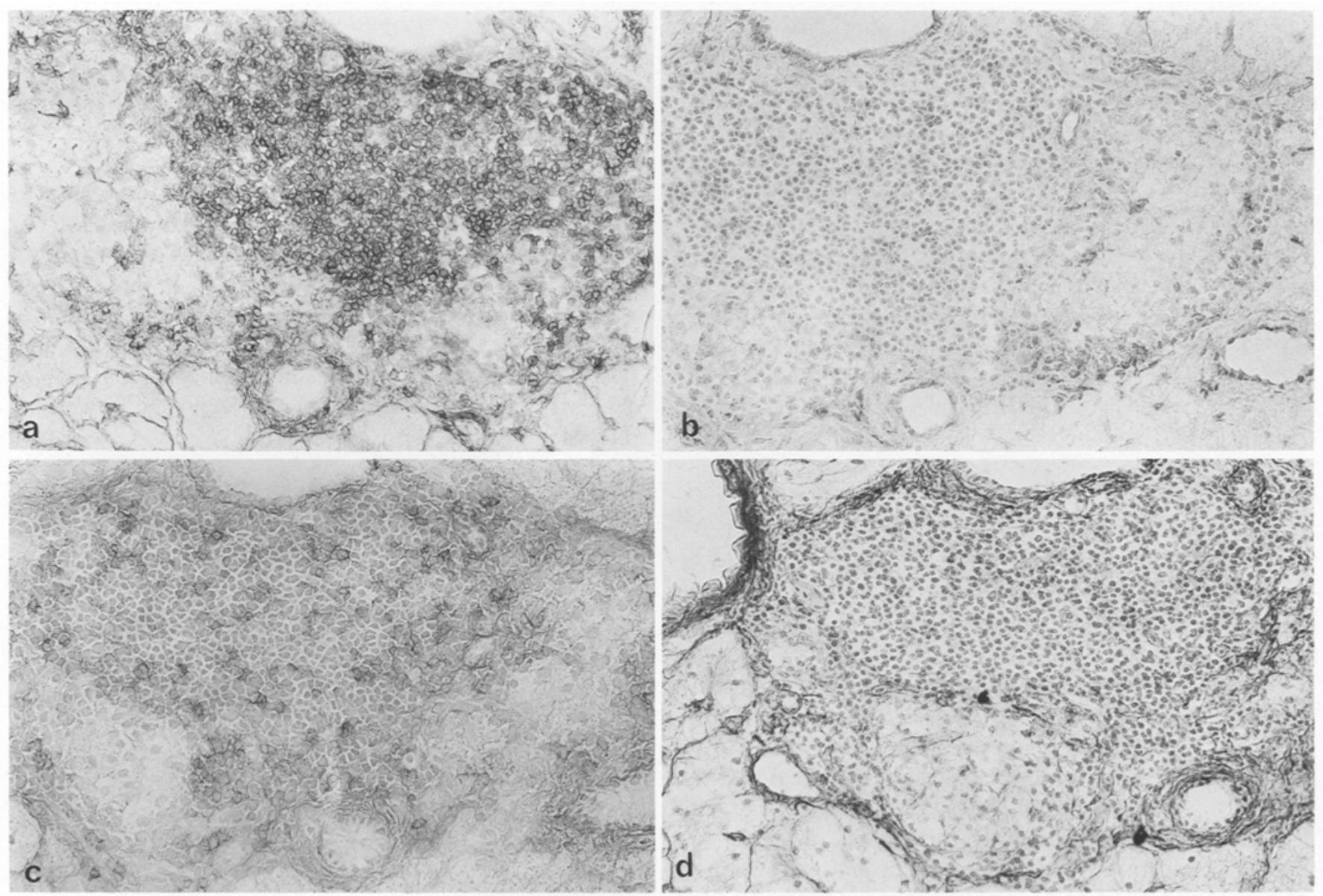

Fig. 1a-d. Immunohistochemical staining of an NOD mouse islet at age 22 weeks. Consecutive slices of the same islet were stained with the following antibodies: a anti-IgM; b anti-asialo GM 1; canti-Lyt-1; and d anti-Lyt-2, respectively

ter, Massachussetts, USA) as antigen. Existence of the antibody was defined as being present when $50 \%$ or more viable cells were associated with anti-mouse IgG antibody (FITC).

\section{Morphological examination}

A portion of each pancreas was excised, immediately frozen and stored at $-70^{\circ} \mathrm{C}$ before use. Sections ( $4 \mu \mathrm{m}$ thick) were cut on a cryostat, and subsequently stained with two immuno-peroxidase methods to demonstrate various lymphocyte markers. For the demonstration of IgM or asialo-GM1-positive cells, a three-step peroxidase-anti-peroxidase-complex method was used [8], with rabbit anti-mouse IgM antibody (Bionetics) and rabbit anti-asialo-GM1 antibody (Wakoh) as first antibodies. For the identification of T-lymphocyte subsets, the avidin-biotin-peroxidase method was used [9], with anti-Lyt-1 and anti-Lyt-2 (Becton Dickinson) as first antibodies.

\section{Results}

Anti-lymphocyte antibodies were maximal at 3 weeks of age (albeit the youngest age studied) and decreased thereafter. ICSA were present at week 6 , reaching maximal prevalence $(50 \%)$ between $12-18$ weeks of age and appeared subsequently to decrease. Since there were no sex differences in the prevalence of these antibodies, the results of both sexes are combined (Table 1).

Pancreatic insulin concentrations in both sexes were found to be $150-200 \mathrm{ng} / \mathrm{mg}$ wet weight between 3-6 weeks of age. The insulin concentration in males decreased to a level of $100 \mathrm{ng} / \mathrm{mg}$ wet weight after 12 weeks and remained constant thereafter. Pancreatic 
insulin in females progressively decreased after 6 weeks and attained a level of $14-26 \mathrm{ng} / \mathrm{mg}$ wet weight in $75 \%$ of mice at 22 weeks of age.

Mononuclear cell infiltration into pancreatic islets began at age 6 weeks in both sexes. These mononuclear cells were located at the margins of the islets where connective tissue with small vessels and ducts are often present.

Immunohistochemically, IgM-positive (B) lymphocytes appeared to be most numerous among the mononuclear cells. Although less numerous, there were Lyt1-positive (helper) and Lyt-2-positive (cytotoxic) T-lymphocytes among the B-lymphocytes.

Small numbers of asialo-GM 1-positive (natural killer) cells were also scattered among the infiltrated cells. B-lymphocytes in the infiltrates became more dominant at later ages. At 22 weeks of age, B-lymphocytes constituted the follicle-like structure and T-lymphocytes and a few natural killer cells were distributed in and around the B-lymphocyte area (Fig.1).

\section{Discussion}

The appearance of anti-lymphocyte antibodies in NOD mice at an early age may be an important indication of an autoimmune nature in these animals [10] and may also be one of the causes of lymphocytopenia previously described [3]. ICSA were noted with the appearance of mononuclear cell infiltration and they continued to exist in the plasma during $\beta$-cell destruction. The disappearance of ICSA in 22-week-old animals may indicate that islet mass had decreased to an insufficient amount to provide antigen to the immune system. The results suggest that measurement of ICSA could provide a good index for the existence of $\beta$-cell destruction.

On the other hand, islet cell cytoplasmic antibodies have been reported to appear before the initiation of cell infiltration [11]. The relationship between these two types of antibodies and the pathogenesis of diabetes in NOD mice may be different. The decrease of pancreatic insulin concentration in the animals in parallel with cell infiltration clearly indicates that diabetes of NOD mice is the result of $\beta$-cell loss of islet tissue caused by an immunological process [12].

In man, the most common lymphocyte reaction of tissue damage in vivo is the random infiltration of $T$ lymphocytes, with various helper-inducer/suppressor cytotoxic cell ratios, intermingled with small numbers of B-lymphocytes. Less frequently, the lymphocytic reaction can take the form of lymphoid structure formation: well developed follicles and T-cell regions can be observed in the involved sites. These are common findings in an autoimmune disease, e. g., in hepatic primary biliary cirrhosis, in autoimmune chronic thryoiditis, in salivary glands associated with Sjörgren's syndrome.

The present study clearly demonstrates that the latter type of lymphocyte reaction took place in pancreatic islets of NOD mice. It is hightly probable that the lym- phoid structures formed in the islets are involved with an abnormal humoral and cellular immune process that is similar to that which occurs in human autoimmune diseases, although the details of this process remain to be clarified.

Acknowledgements. This work was partly supported by Grant-in-Aid Scientific Research 457590 from the Ministry of Education. The authors thank Professor L Kumagai, University of California Davis for his criticism during the preparation of the manuscript. We also wish to thank Ms. T. Takahashi and Ms. K. Nakazato for their technical assistance.

\section{References}

1. Makino S, Kunimoto K, Muraoka Y, Mizushima Y, Katagiri K, Tochino Y (1980) Breeding of a non-obese, diabetic strain of mice. Exp Anim 29: 1-13

2. Makino S, Kunimoto K, Muraoka Y, Katagiri K (1981) Effect of castration on the appearance of diabetes in NOD mice. Exp Anim $30: 137-140$

3. Kataoka S, Satoh J, Fujiya H, Toyota T, Suzuki R, Itoh K, Kumagai $\mathrm{K}$ (1983) Immunologic aspects of the nonobese diabetic mouse. Diabetes 32: 247-253

4. Fujita T, Yui R, Kusumoto Y, Serizawa Y, Makino S, Tochino Y (1982) Lymphocytic insulitis in a 'Non-obese diabetic strain' of mice: an immunohistochemical and electron microscope investigation. Biomed Res 3: 429-443

5. Kanazawa Y, Kuzuya T, Ide T, Kosaka K (1966) Plasma insulin responses to glucose in femoral, hepatic and pancreatic veins in dogs. Am J Physiol 211: 442-448

6. Lernmark A, Kanatsuna T, Patzelt C, Diakoumis K, Carroll R, Rubenstein AH, Steiner DF (1980) Antibodies directed against the pancreatic islet cell plasma membrane, detection and specificity. Diabetologia 19: 445-451

7. Lernmark $\AA$, Freedman ZR, Hofmann C, Rubenstein AH, Steiner DF, Jackson RL, Winter RJ, Traisman HS (1978) Islet cell surface antibodies in juvenile diabetes mellitus. New Engl J Med 299: 375-386

8. Stein H, Bonk A, Tolksdorf G, Lennert K, Rodt H, Gerdes J (1980) Immunohistologic analysis of the organization of normal lymphoid tissue and non-Hodgkin's lymphomas. J Histochem Cytochem 28: 746-760

9. Hsu S-M, Raine L, Fanger H (1981) Use of avidin-biotin-peroxidase complex $(\mathrm{ABC})$ in immunoperoxidase techniques. J Histochem Cytochem 29: $577-580$

10. Theofilopoulos AN (1982) Autoimmunity. In: Stites DP, Stobo JD, Fundenberg HH, Wells JV (eds) Basic and clinical immunology 4th edn. Lange Medical Publications, Los Altos, California, USA, pp 156-188

11. Toyota T, Kataoka S, Sato J, Fujiya H, Hayashida Y, Goto Y, Kumagai K (1983) Islet-cell antibody and immunologic aspects of NOD mice. In: Mimura G, Baba S, Goto Y, Köbberling J (eds) Clinico-genetic genesis of diabetes mellitus. Excerpta Medica, Amsterdam. International Congress Series 597, pp 185-192

12. Tarui S, Mamba M, Yamada K, Nonaka K (1983) Viral induced diabetes associated with insulitis. In: Mongola EN (ed) Diabetes 1982. Excerpta Medica, Amsterdam. International Congress Series $600, \mathrm{pp} 107-115$

Dr. Y. Kanazawa

Third Department of Internal Medicine

Faculty of Medicine

University of Tokyo

Hongo 7-3-1

Bunkyo-ku

Tokyo

Japan 113 